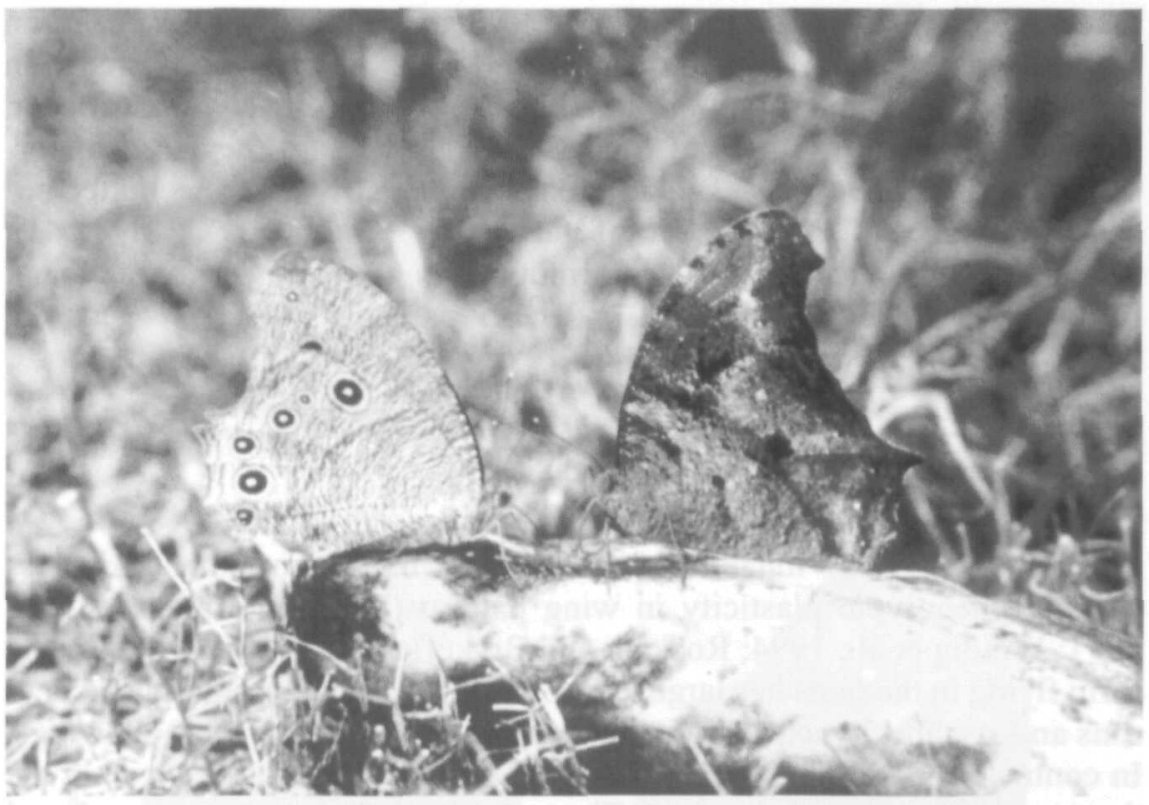

Figure 1. The alternative seasonal forms of the evening brown Melanitis leda feeding on ripe banana. The butterfly to the left is a wet season form with conspicuous eyespots. The other is of the dry season form without eyespots and resembles a dead leaf.

inactively on the carpet of dead leaf litter. Temperatures rise again several weeks before the rains begin. During this latter period the butterflies become more active, mate and mature their eggs (Brakefield and Reitsma, 1991).

Butterflies of the wet season form fly in a hot and humid period with widely available larval food plants and adult food. In similar conditions in the laboratory, females mate soon after eclosion and can begin to oviposit within 2-3 days (Kooi et al., 1997). They lay 300-400 eggs over 3 and 4 weeks (Brakefield and Kesbeke, 1995). Eggs are laid on a variety of grasses, especially Oplismenus spp. (Kooi et al., 1996). Preadult development occurs in 3-4 weeks (see Brakefield and Mazzotta, 1995). Adults feed on fallen fruit, including from Ficus trees (Brakefield and Kesbeke, 1995). It is thus a season of apparently freely available larval and adult resources with a favourable climate for growth and adult activity.

In contrast, adults of the dry season form develop as larvae under comparatively low temperature and humidity. They have no choice but to feed on grasses which become increasingly senescent and desiccated as larval growth progresses. Pre-adult development is much longer at about 6-8 weeks (see Brakefield and Mazzotta, 1995). After adult eclosion in a common environment in the laboratory, females of the dry season form tend to 


\section{Environmental Stress, Adaptation and Evolution}

Edited by R. Bijlsma

V. Loeschcke 


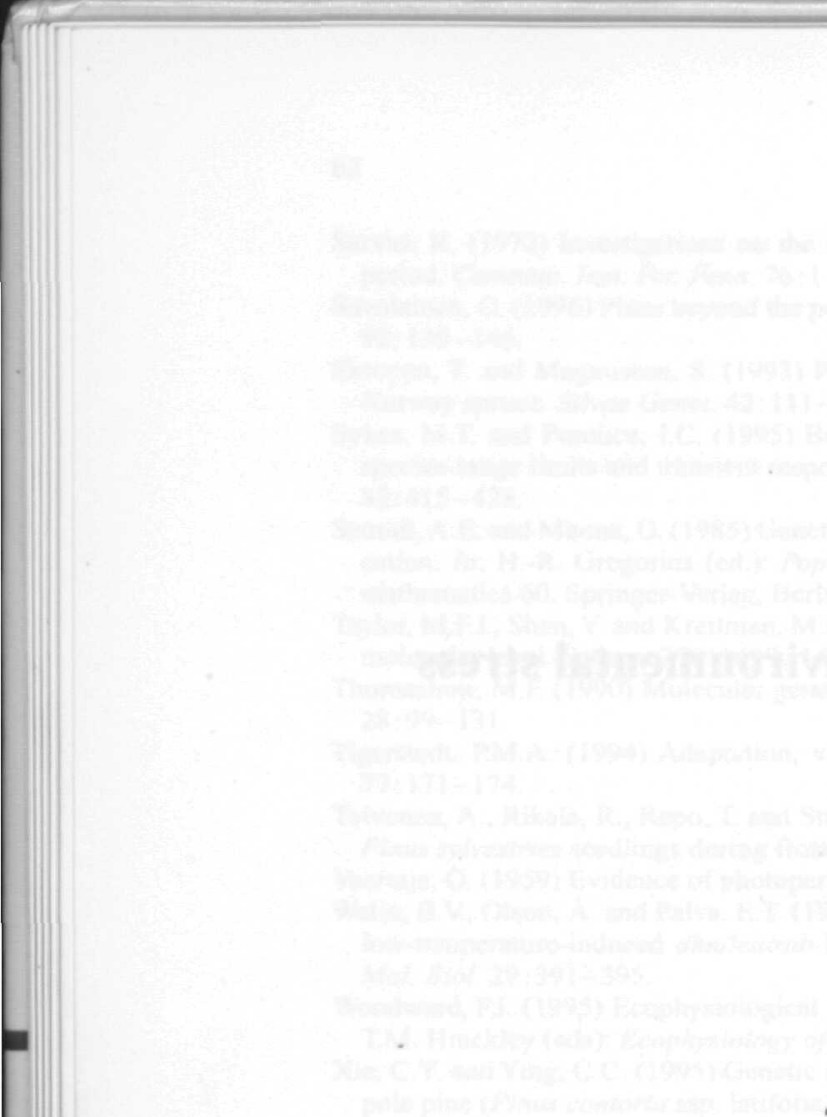




\title{
Phenotypic plasticity and fluctuating asymmetry as responses to environmental stress in the butterfly Bicyclus anynana
}

\author{
Paul M. Brakefield \\ Institute of Evolutionary and Ecological Sciences, Leiden University, P.O. Box 9516, \\ NL-2300 RA Leiden, The Netherlands
}

Summary. Butterflies of the genus Bicyclus inhabiting wet-dry seasonal environments in Africa express striking seasonal polyphenism. This paper describes this example of phenotypic plasticity in the context of an evolutionary response to alternative seasons, one of which is favourable for growth and reproduction while the other is a stress environment, limiting in terms of larval growth and adult survival. The seasonal forms reflect alternative adult phenotypes which involve both morphological (wing pattern) and life history traits. The genetic and physiological coupling of these traits involves mediation by a common hormonal system. Finally, I show that the eyespot patterns on the wings of these butterflies also offer potential for studying the mechanisms of fluctuating asymmetry and its interactions with environmental stress.

\section{Introduction}

Phenotypic plasticity occurs when variability in an environmental stimulus leads individuals of the same genotype to develop into alternative phenotypes (see Stearns, 1989, 1992). Because phenotypic plasticity can be an adaptation to variable environments, it is becoming increasingly recognised that understanding its regulation and evolution may offer general insights into the genetic and developmental bases of morphological evolution (e.g. Via, 1993; Via et al., 1995; Gotthard and Nylin, 1995; Brakefield et al., 1996; Pigliucci, 1996). However, phenotypic plasticity has been considered less frequently in the context of the evolution of responses to stress environments (see Scharloo, 1989; Harvell, 1990; Spitze, 1992).

Many of the 80 or so species of Bicyclus butterflies inhabit highly seasonal environments in Africa south of the Sahara. These species are characterised by a wet season adult form which develops and flies in a favourable climate and a dry season form which develops in progressively less favourable conditions before persisting as adults through a long, dry season until reproducing. The most obvious difference in wing pattern between these alternative phenotypes is the presence of large, conspicuous ventral eyespots in the wet season form and their near absence in the dry season form. In this chapter, I will review our understanding of seasonal polyphenism in the tropical butterfly, B. anynana, as gained from an integrated approach. This will indicate how the phenomenon can be viewed as 
an example of adaptive phenotypic plasticity in response to variability in environmental stress.

In addition, I will show how the eyespots of $B$. anynana provide potential for understanding mechanisms of fluctuating asymmetry in morphological traits in response to stress. Fluctuating asymmetry (FA) is a term describing the unsigned difference between the phenotypic values of characters on the left and right sides of individual organisms (Møller, this volume). When fitness depends on morphology, individuals which can develop the phenotype reliably or show greater developmental stability should be more fit (Palmer, 1996). The departure of individuals from bilateral symmetry, as measured by FA, has frequently been suggested as an appropriate index of genetic or environmental health (e.g. Leary and Allendorf, 1989) and of the effects of stress (Parsons, 1990, 1992). Experimental work shows that females of some organisms prefer to mate with more symmetric males (Watson and Thornhill, 1994) and that some pollinating insects are more likely to visit symmetric flowers (Møller and Eriksson, 1995). While the proximate cause of increased FA may frequently be environmental stress, the ability to execute developmental programmes correctly and uniformly in the face of such stress must have a genetic basis. The measurement of FA is thus an attempt to assess the ability of an individual to stabilise or canalise development to achieve the morphogenetic ideal of perfect symmetry. Studies of eyespots may provide answers to some of the questions about the mechanisms of FA and developmental stability in the face of stress environments.

\section{Population biology of Bicyclus species in seasonal environments}

Many species of satyrine butterfly are adapted to the wet-dry seasonal environments of Africa (Fig. 1; Brakefield and Larsen, 1984; Brakefield, 1987). The wet season form of each of five sympatric species of Bicyclus in a forest edge biotope in Malawi flies actively during months with high rainfall from late December until May (Brakefield and Reitsma, 1991; Windig et al., 1994; Brakefield and Mazzotta, 1995; Roskam and Brakefield, 1996). The adult butterflies are active. They rest on, and fly amongst the luxuriant growth of herbs and grasses. There are two overlapping generations in the rains, the first arising from eggs laid by dry season form butterflies after the early rains of late November and December. Some males from the first emergence probably survive long enough to mate with females from the second. Butterflies of the second generation of the wet season form lay eggs which produce adults of the dry season form at the transition from wet to dry in May and June. These latter butterflies must survive at least 6 months before they can oviposit on freshly growing grasses at the beginning of the next wet season. Most of the duration of the dry season in Malawi is cool. The dry season form butterflies tend to rest 